\title{
Adult Intussusception due to Cecal Lymphangioma: A Case Report
}

\author{
Dong Il Kim, Hyung Il Seo, Jae Hun Kim, Hyun Sung Kim, Hong Jae Jo \\ Department of Surgery, Pusan National University School of Medicine, Busan, Korea
}

We present a rare case of adult intussusception due to cecal lymphangioma. A 30-year-old female was admitted to our hospital with abdominal pain and a palpatable mass on the right lower quadrant. Preoperative radiologic studies by ultrasound and computed tomography showed ileocolic intussusception with a multiseptated cystic tumor as a leading point on the cecum. An ileocecectomy was performed, and the postoperative course was uneventful. Histopathology showed a cecal lymphangioma. Although endoscopic polypectomy or endoscopic mucosal resection is recommended for pedunculated or semi-pedunculated colonic lymphangiomas less than $2 \mathrm{~cm}$ in size, it is proper to treat large or symptomatic colonic lymphangiomas with limited a bowel resection or a tumor resection.

Keywords: Intussusception; Cecal lymphangioma; Colon lymphangioma

\section{INTRODUCTION}

Adult intussusception accounts for 5-10\% of all intussusecptions, and it has a leading point in more than $90 \%$ of all cases $[1,2]$. Finding the leading point of adult intussusception is difficult for physicians because of its rare incidence and nonspecific clinical manifestations. The most benign etiologies of colonic intussusception are lipoma and adenoma. Colonic lymphangioma may be a rare cause of adult intussuseption, and only five cases have reported in the English and the Japanese literature [3-7]. Recently, colonic lymphangioma has been diagnosed more frequently during colonoscopy and has been removed by using an endoscopic procedure [8]. However, large colonic lymphangiomas with complications require surgical resection. We report a case of adult intussusceptoin due to cecal lymphangioma that was diagnosed by imaging studies before surgery. We also present a review of associated articles.

Received: Decemver 21, 2010 Accepted: March 27, 2011

Correspondence to: Hyung II Seo, M.D.

Department of Surgery, Pusan National University School of Medicine,

1-10 Ami-dong, Soe-gu, Busan 602-739, Korea

Tel: +82-51-240-7238, Fax: +82-51-247-1365

E-mail:seohi71@hanmail.net

(C) 2011 The Korean Society of Coloproctology

This is an open-access article distributed under the terms of the Creative Commons Attribution NonCommercial License (http://creativecommons.org/licenses/by-nc/3.0) which permits unrestricted noncommercial use, distribution, and reproduction in any medium, provided the original work is properly cited

\section{CASE REPORT}

A 30-year-old female was admitted to our hospital with right lower abdominal pain for one day. Her history was unremarkable. On admission, her body temperature was $37^{\circ} \mathrm{C}$, her blood pressure was $120 / 80 \mathrm{~mm} \mathrm{Hg}$, and her heart rate was 78 beats/min. A physical examination revealed right lower quadrant pain and tenderness, but no rebound tenderness was detected. Laboratory tests, including a peripheral blood test, a biochemical test and a urinalysis, were all normal, except for the white blood cell count (12,700/ $\mathrm{mm}^{3}$ ). The plain abdomen exhibited no remarkable abnormal findings. Ultrasonography showed a multiseptated cystic mass associated with an intussusception at the cecum. The color Doppler image showed that flow signals at the bowel wall were preserved (Fig. 1). Computed tomography (CT) revealed the same cystic lesion in the cecum and showed a "bowel within bowel" configuration, as well as vessels and mesenteric fat within the bowel's lumen (Fig. 2).

An emergency laparotomy was performed, with a diagnosis of intussusception due to cecal lymphangioma. During the operation, we found an ileocolic intussusceptions, and an ilececectomy was performed after manual reduction. Macroscopically, a 9-cm submucosal tumor with fluctuations and with a round, smooth, and broad base was seen in the cecum (Fig. 3). The cystic lesion was filled with focal hemorrhage. Histological examination found that the cyst was located below the normal mucosal membrane and was surrounded by flat endothelial cells (Fig. 4). Immunohistochemstry showed negative for carcinoembrionic antigen (CEA) and pos- 


\section{Coloproctology Dong II Kim, et al.}

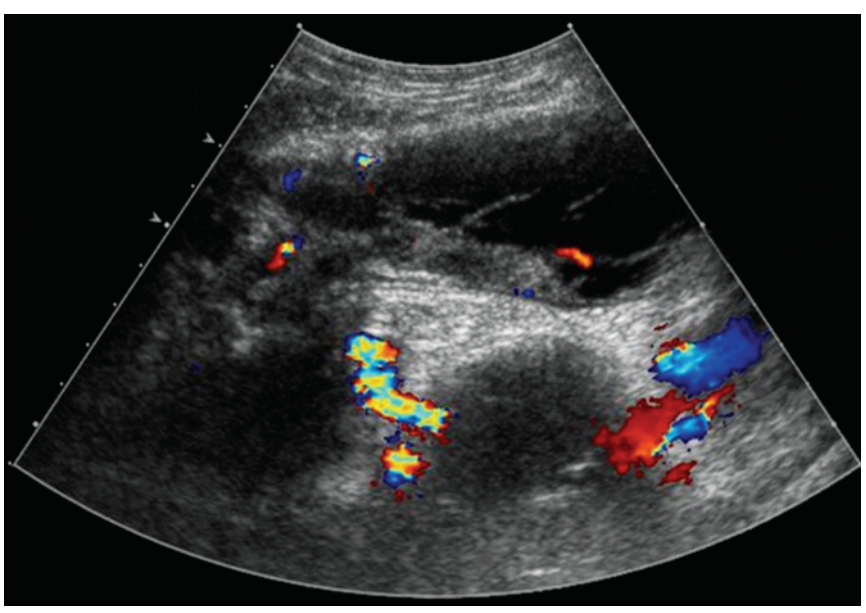

Fig. 1. Ultrasonography shows a well-demarcated multiseptated cystic mass associated with intussusception in the transverse colon. The color Doppler image showed that flow signals at the bowel wall were preserved.

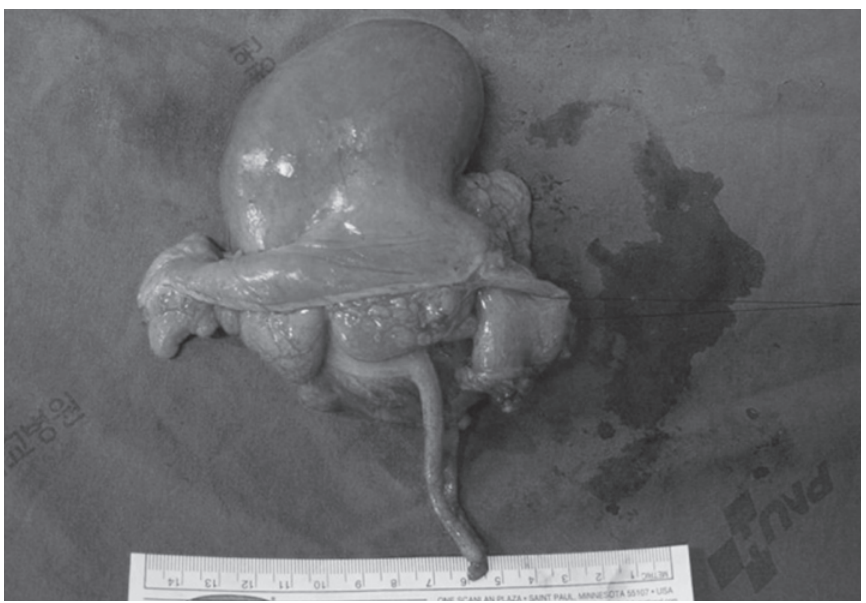

Fig. 3. During the operation, we found an ileocolic intussusception. Macroscopically, a 9-cm submucosal tumor with a round, smooth, broad base was seen in the cecum.

itive for factor VIII. The histological diagnosis confirmed a cecal lymphangioma. The patient's postoperative course was uneventful, and she was discharged five days after the operation.

\section{DISCUSSION}

Lymphangioma is a benign tumor that consists of several expanded lymphatics surrounded by benign endothelial cells and cystic spaces containing chylous, seroangeous or serous material. Lymphangioma occurs most often in the head and neck, axilla, or groin in young children, but it is incidentally diagnosed during adulthood in the intra-abdomen and retroperitoneum. Lymphangioma in the gastrointestinal tract is extremely rare. Besides the stomach, lymphagiomas of the gastrointestinal tract have been reported to

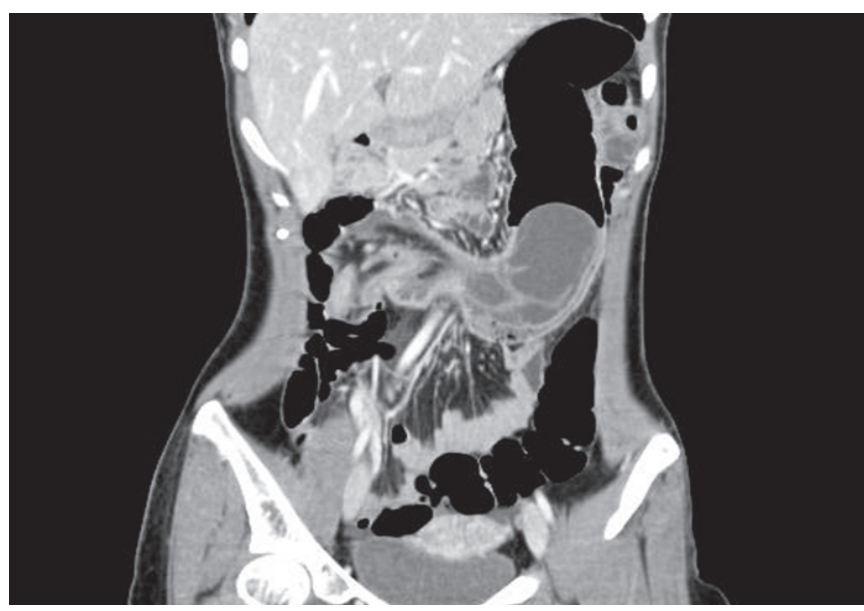

Fig. 2. CT shows a low-density multilocular cystic lesion with septation originating from the cecum, and a bowel-within-bowel configuration, as well as vessels and mesenteric fat within the bowel's lumen, is seen.

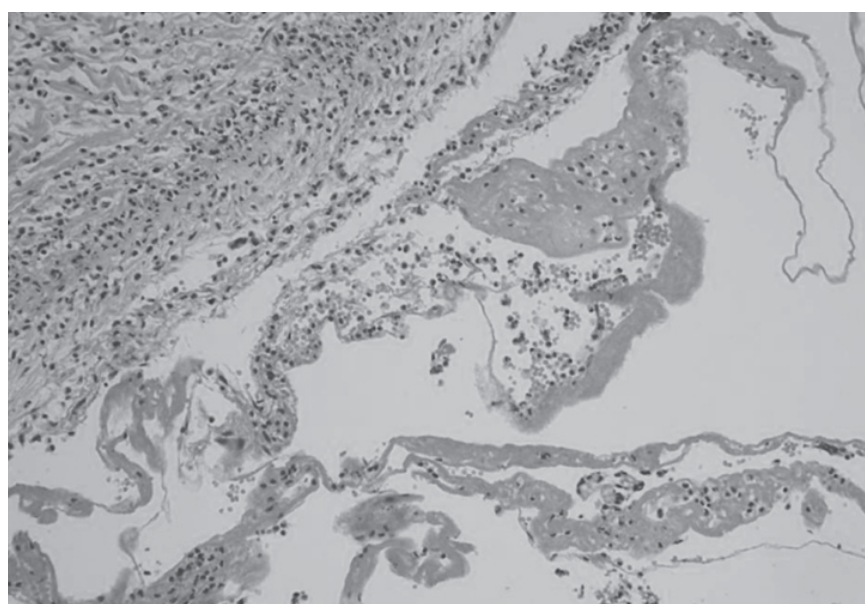

Fig. 4. The mass showed dilated spaces lined by a flattened endothelium. A scattering of lymphocytes was present in the stroma $(\mathrm{H} \& \mathrm{E}$, $\times 100)$.

occur in the small intestine (mostly in the jejunum), the esophagus, and the colon [9].

Cystic lymphangioma of the colon is also extremely rare; only 79 cases of colonic lymphangioma have been reported in the English and Japanese literature [8]. A colonic lymphangioma is small and nearly asymptomatic, so most reported cases are detected incidentally during colonoscopy or barium enema [8]. If symptoms arise, patients complain of an acute abdominal pain, flank pain, nausea and vomiting, which clinically mimic symptoms of acute appendicitis or intestinal obstruction. Our patient presented with acute abdominal pain for one day and a palpatable mass, with tenderness on her right lower quadrant.

Intussusception in adults develops infrequently and has leading points. These include tumors (52\%), postoperative causes (36\%), 
Table 1. Reported cases of intussusception with colonic lymphangioma

\begin{tabular}{lcccccc}
\hline Author & Age & Sex & Site & $\begin{array}{c}\text { Incomplete fixation } \\
\text { of colon }\end{array}$ & Size (cm) & Operation \\
\hline Nagle et al. [3] & 43 & Female & Cecum & Yes & $10 \times 5$ & Right Hemicolectomy \\
Matsui et al. [4] & 40 & Female & Cecum & Yes & $7 \times 5 \times 4$ & lleocecectomy \\
Wan et al. [5] & 28 & Female & Cecum & No & 7 & Right Hemicolectomy \\
Matsuba et al. [6] & 39 & Female & Cecum & Yes & $9 \times 6$ & Ileocecectomy \\
Kim et al. [7] & 32 & Female & Transverse Colon & Not described & $2.5 \times 3.5 \times 5$ & Segmental Resection \\
Present & 30 & Female & Cecum & Yes & $9 \times 5$ & lleocecectomy \\
\hline
\end{tabular}

idiopathic causes (8\%), and so on [2]. For the diagnosis of intussusception in adults, computed tomography has been reported to be the most useful method [10]. Radiologic studies showed that our patient's ileocecal intussusception occurred due to a cecal cystic mass, but she had no sign of an intestinal obstruction. The CT findings of intussusception, as shown in our case, are characterized by the presence of a thickened bowel wall, as well as soft tissue and fat attenuation [11]. The lead point detected in our case was a 9-cm cystic mass in the cecum. Ultrasonography confirmed the cecal cystic mass, and our radiologist suggested intussusception due to a cecal lymphangioma. To our knowledge, only six cases (including our present case) of colonic lymphangioma in adults have developed into an intussusception; five lesions were located in the cecum and one in the transverse colon (Table 1) [3-7]. All were in females, all the tumors were larger than $5 \mathrm{~cm}$, and all patients underwent a laparotomy. Incomplete fixation of the colon and cecum was described in four patients, and we thought this might have been partially responsible for the chronic recurrent intussusception. Even though an endoscopic polypectomy or an endoscopic mucosal resection may be recommended for pedunculated or semipedunculated colonic lymphangiomas less than $2 \mathrm{~cm}$ in size [8, 12,13 ], a large or symptomatic colonic lymphangioma should be treated with a limited bowel resection or a tumor resection.

\section{CONFLICT OF INTEREST}

No potential conflict of interest relevant to this article was reported.

\section{REFERENCES}

1. Prater JM, Olshemski FC. Adult intussusception. Am Fam Physician 1993;47:447-52.
2. Agha FP. Intussusception in adults. AJR Am J Roentgenol 1986; 146:527-31.

3. Nagle R. Lymphangiomatous hamartoma with intussusception of the caput caeci. Br J Surg 1968;55:879-80.

4. Matsui A, Okajima K, Ishii M, Namio H, Kawanishi M, Fujii Y, et al. Lymphangioma of the cecum with intussusceptions: a case report and review of literature. J Jpn Pract Surg Soc 1986;47:234-9.

5. Wan YL, Lee TY, Hung CF, Ng KK. Ultrasound and CT findings of a cecal lymphangioma presenting with intussusception. Eur J Radiol 1998;27:77-9.

6. Matsuba Y, Mizuiri H, Murata T, Niimi K. Adult intussusception due to lymphangioma of the colon. J Gastroenterol 2003;38:181-5.

7. Kim TO, Lee JH, Kim GH, Heo J, Kang DH, Song GA, et al. Adult intussusception caused by cystic lymphangioma of the colon: a rare case report. World J Gastroenterol 2006;12:2130-2.

8. Kuramoto S, Sakai S, Tsuda K, Kaminishi M, Ihara O, Oohara T, et al. Lymphangioma of the large intestine: report of a case. Dis Colon Rectum 1988;31:900-5.

9. Losanoff JE, Richman BW, El-Sherif A, Rider KD, Jones JW. Mesenteric cystic lymphangioma. J Am Coll Surg 2003;196:598-603.

10. Azar T, Berger DL. Adult intussusception. Ann Surg 1997;226: 134-8.

11. Lorigan JG, DuBrow RA. The computed tomographic appearances and clinical significance of intussusception in adults with malignant neoplasms. Br J Radiol 1990;63:257-62.

12. Hatada T, Ikeda H, Tanigawa A, Fujiwara Y, Hanada Y, Yamamura T. Lymphangioma of the colon: a case report and review of the Japanese literature. Acta Gastroenterol Belg 2000;63:239-41.

13. Kochman ML, Wiersema MJ, Hawes RH, Canal D, Wiersema L. Preoperative diagnosis of cystic lymphangioma of the colon by endoscopic ultrasound. Gastrointest Endosc 1997;45:204-6. 